\title{
Magnetic Method Surveying and Its Application for the Concealed Ore-Bodies Prospecting of Laba Porphyry Molybdenum Ore Field in Shangri-La, Northwestern Yunnan Province, China
}

\author{
Nguyen Ba Dai, Chuan Dong Xue, Kun Xiang, Tran Trong Lap, Qureshi Javed Akhter, \\ Shi Lei Li \\ Department of Earth Sciences, Kunming University of Science and Technology, Kunming, China \\ Email: nguyenbadai2001@gmail.com, cdxue001@aliyun.com
}

Received February 2014

\begin{abstract}
Recently, a number of large molybdenum (-copper) deposits have been discovered successively in the Laba area, Shangri-La county, northwestern Yunnan province. The investigation confirmed that there is a superlarge porphyry-skarn hydrothermal vein type molybdenum-polymetallicmetallogenic system with the total prediction reservoir of more than $150 \mathrm{mt}$ molybdenum. The porphyry intrusions contributed to the mineralization closely, the superficial little vein molybdenum (-copper, lead, silver) ore-bodies are usually located in faults and fractures, and the deep porphyry type ore-bodies occurred in the granodiorite porphyries, the skarn type ore-bodies occurred in the contact zone intrused into Triassic limestone or Permian basalts. Laba ore block is a new exploration area with great prospecting potential. In order to reduce the target area and guide the further exploration work, the magnetic method measurement about 3.3 square kilometres was carried out in the ore field. This paper presents an application of analyzing the horizontal and vertical derivative, using Fast Fourier Transform (FFT) filter (FFT high-pass, low-pass, cosine roll-off, suscepbility), calculated spectra frequency energy to predict the depth and intensity of the apparent remanence magnetization of source (Hilbert). The calculated results and magnetic anomalous show that the remanence anomaly is caused by the intrusions into the Triassic limestone and Permian basalts with small anomalies, and the depth of located source is not great. We have identified a number of positions to the three drilled well, the drilled result specify interpretation with very high accuracy. The magnetic method is helpful to identify porphyry mineralization, and judge the shape and depth of the concealed ore-bearing intrusive bodies under the similar geological condition.
\end{abstract}

\section{Keywords}

Magnetic Method, Physical Property Parameters, Concealed Ore-Bodies Prospecting, Laba Porphyry Molybdenum (-Copper) Ore Field, Northwestern Yunnan Province 


\section{Introduction}

In the Laba town and surrounding area about 100 square kilometres in Shangri-La county, northwestern Yunnan province, there distributed large amounts of smaller copper-, lead-, and zinc-polymetallic deposits and mineralization spots. Through much detail geological work during the past several decade, the advance of mineral resources prospecting exploration is little, and the know ore deposits occurred in the not wide range area. Till to 2010, the No. KT1 molybdenum (-copper)-rich orebody in Tongchanggou ore block was firstly explored by Geology Investigation Institute of Yunnan Bureau of Geological Survey sponsored by Yunnan Copper Industry Group Company (e.g., Li et al., 2012). After that, a number of molybdenum (-copper) deposits have been discovered successively, and porphyry intrusions contributed to the mineralization. The superficial little vein or veinlet molybdenum (-copper, lead, silver) ore-bodies are usually located in secondary fractures and the intersection part of different direction faults, and the deep porphyry type ore-bodies occurred in the monzonitic granite to granodiorite porphyries, the skarn type ore-bodies occurred in the contact zone intrused with Triassic limestone or Permian basalts in a certain range. Up to now, the Laba molybdenum (-copper) deposit has become a super large porphyry deposit with resources reserves of 63.5 mt Mo @ 0.11\%, associated with 33.7kt Co@ 0.22\% and Au 14.7t @ 0.65ppm. The investigation confirmed that there is a super large porphyry-skarn hydrothermal vein type molybdenum-polymetallicmetallogenic system, and the total prediction molybdenum reservoir will be more than $150 \mathrm{mt}$. The exploration and research work is still in progress, the reserves increase gradually.

The Laba ore block is a new prospecting exploration area with distance about 3 kilometres north to the Tongchanggou ore block, and the prospecting potential is great. Field investigation shows that concealed granite intrusions may exist in the depth, and mineralization was related to magmatic intrusion. But the area covering layer thickness, morphology of ore bearing rock buried depth, stratigraphy and structural rule is unknown, the exploration work deployment is of poor effectiveness. In order to reduce the target area rapidly, and guide the further mineral exploration and evaluation work effectively, the magnetic method measurement work (EunJung et al., 2011; Vanessa et al., 2013; Wang et al., 2012; Yang et al., 2011) for the concealed ore-bodies prospecting was carried out starting from July 2012. Totally, we have surveyed finished the magneticzation surveying of the Laba ore field more than 3 square kilometres. This paper puts forward a new data processing method, and presents an application of analyzing the derivative horizontally and vertically, using Fast Fourier Transform (FFT) filter for rectangular window applied to horizontal derivative. The aim is to calculate spectra frequency energy to predict the depth and intensity of the apparent remanence magnetization of source (Hilbert) (Alanna \& Yára, 2009; Fabio, 2012; Ilya \& Ahmed, 2009; Maysam et al., 2013; Pejman et al., 2011; Stocco et al., 2009), and is applied to calculate magnetic data anomalous. The results show that, the remanence anomaly is caused by the intrusion into the Triassic limestone and Permian basalts with small anomalies, and the depth of located source is not great. We have identified a number of positions to the three drilled well, the result specify interpretation with very high accuracy. And it can judge the shape and depth of the concealed ore-bearing intrusive bodies. The magnetic method is helpful to identify porphyry molybdenum (-copper) mineralization under the similar geological condition.

\section{Geology Background}

The Laba molybdenum (-copper) polymetallic deposit is located in the western margin of the Yangtze block, and is adjacent to the southern connection part of the Yangtze block and the Zhongdian island arc belt, which belongs to the southern part of the Late Triassic Yidun magmatic arc. The Zhongza block and Jinsha River suture are located to the northwest along the Geza faults zone, and the Garze-Litang suture zone to the northeast. From a regional perspective, the Zhongdian arc is a significant Triassic porphyry and skarn copper-polymetallic district (e.g., Hou et al., 2003), hosting several large deposits, such as Pulang, Xuejiping, Hongshan, Gaochiping and Chundu, as well as many smaller deposits and occurrences under the setting of the Mesozoic arc. But recently, the Late Cretaceous monzonitic granite to granodiorite porphyries with porphyry and skarn molybdenum (-copper) mineralization (e.g., Li et al., 2012; Peng et al., 2014) and lamprophyre has also been identified in Laba area. They exposed diabase dikes and sporadically in a small area. Acid intrusions in the area extend from north to south and the belt passes through Yidun arc and enters the western margin of Yangtze landmass.

The Laba molybdenum (-copper) ore field covering an area of 10 square kilometres is located in Laba town of Logi Xiang in Shangri-La county, northwestern Yunnan province, southwestern China. The deposit has two ore blocks termed the Tongchanggou and the Laba blocks. The Tongchanggou ore block, located in the southeast, 
was discovered in 1985, and the exploration has not completed. The Laba ore block, to the northwest, was only recently discovered and is under exploration.

The wall rocks are dominated by Middle Triassic Beiya group $\left(\mathrm{T}_{2} \mathrm{~b}\right)$ limestone, and Permian Dam group $\left(\mathrm{P}_{2} \mathrm{~d}\right)$ volcanic rocks interbeded with dense shaped limestone, siltstone and sandstone, which underwent contact metamorphism to hornfels and marble "Figure 1". The main structure line orientation is N-NW, and rarely NE. The ore field lies in the northern plunging segment of the NW-trending Baihua Mountain anticline with Permian Dam group $\left(\mathrm{P}_{2} \mathrm{~d}\right)$ basalt in core, and Triassic Beiya group $\left(\mathrm{T}_{2} \mathrm{~b}\right)$ limestone in limbs, the east wing occurred $60^{\circ}$ $50^{\circ}$ angle, the west wing is $280^{\circ}-300^{\circ}$ and angle of $45^{\circ}-60^{\circ}$ "Figure 1". In this area, the main faults are $\mathrm{F}_{1}, \mathrm{~F}_{2}$, $\mathrm{F}_{3}$ and $\mathrm{F}_{4}$ fault. Among them, the $\mathrm{F}_{1}$ fault (Tongchanggou) trending NNE and cuting the anticlinal axis, is the major structures, and also control the distribution of magmatic rocks and related ore deposits. ANNW trending Yanshanianmonzonitic granite to granodiorite porphyry is exposed only in the center of the Laba ore block. The outcrop area is approximately $200 \mathrm{~m}^{2}$ with length of $10-120$ meters and width of 5 - 40 meters, its contact zone with the surrounding sedimentary rocks is not clear. The porphyry is wholly mineralized and hydrothermal metasomatism in the upper part locally displaying skarn type and hydrothermal vein type mineralization in wall rocks, forming a porphyry minerogenetic series. The molybdenum (-copper) ore-bodies have been measured to depth of from 100 to 850 meters.

\section{Research Methods}

\subsection{Magnetic Data Survey}

The magnetic survey work carried out in July 2012, using the Proton Geometric G856 device, which allows the accuracy of $0.5 \mathrm{nT}$. The north-south direction is line survey, the spacing line to line of $100 \mathrm{~m}$, the distance points of $10 \mathrm{~m}$. Using the same accurate measure, it measured diurnal magnetic field. The magnetic field century give by IGMR at July 2012 update, with altitude is $2400 \mathrm{~m}$ of similar altitude of diurnal magnetic field. Survey area is smaller, but the great alter in topography, altitude changing from 2300 - $3200 \mathrm{~m}$ (Figure 2). Therefore, the terrain adjustment is very important. The magnetic field is reduced by $\pm 0.23 \mathrm{nT}$ with alteration in $100 \mathrm{~m}$ altitude.

The obtained results show "Figure 2", the small anomaly of different intensity along north-south direction, along $F_{1}$ fault toward the Logi river, the adjacent coordinate 606100 to 607300 and 3069500 to 3071700 , these magnetic anomaly parameters from $-650 \mathrm{nT}$ to $200 \mathrm{nT}$.

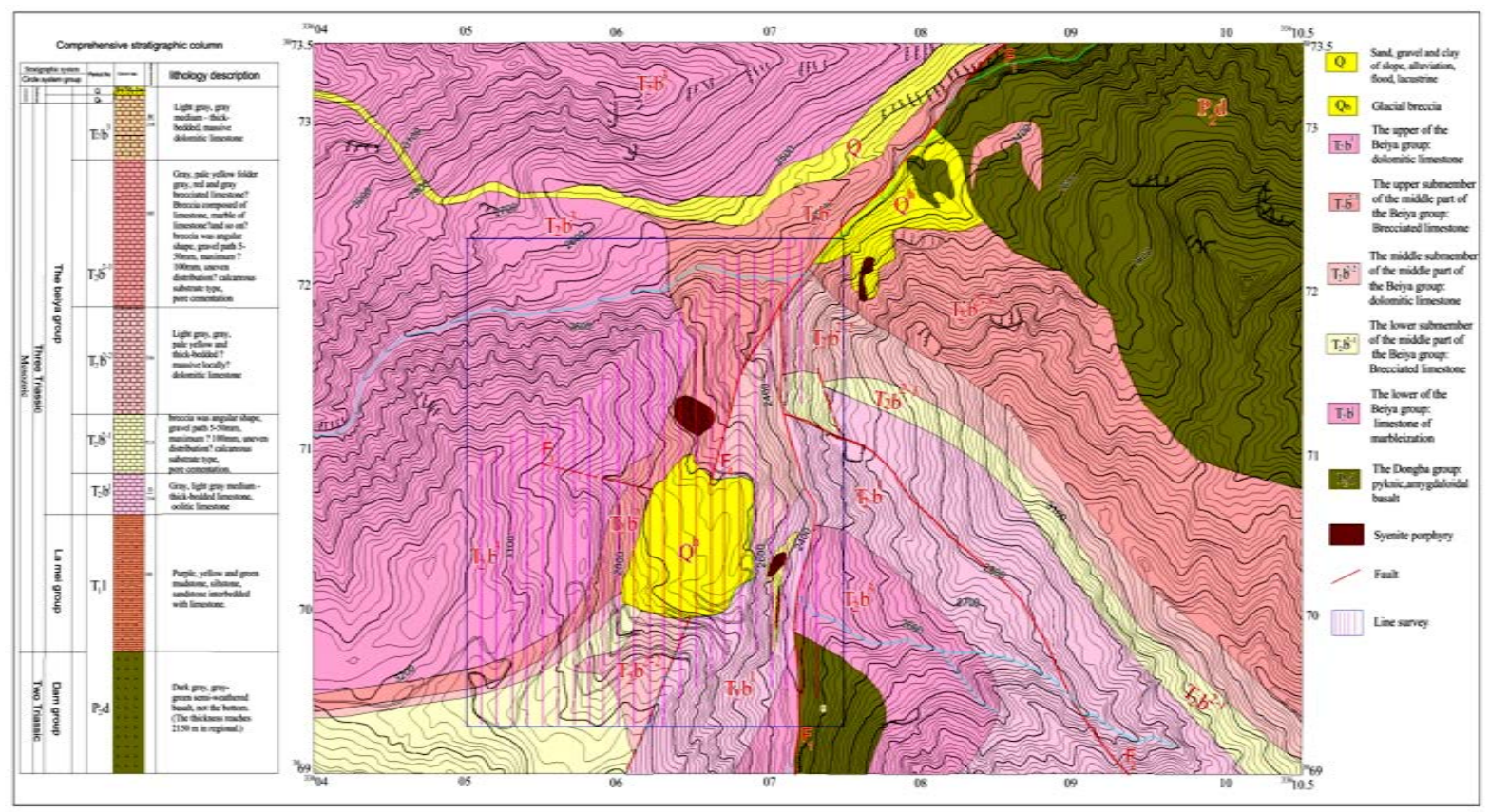

Figure 1. The geological map of Laba molybdenum (-copper) ore field. 


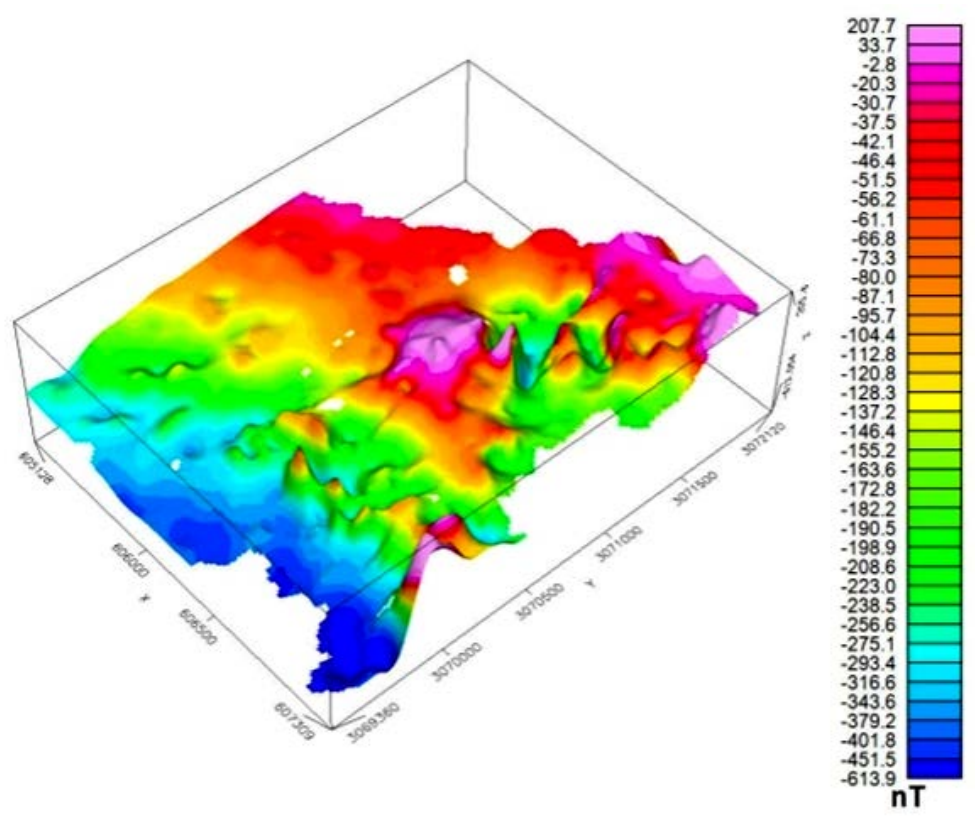

Figure 2. Shangri-La, Laba anomalous magnetic map.

\subsection{Method and Analysis Filter}

The magnetometric study of igneous intrusions is thoroughly linked to the definition of the vector components of the magnetic field:

$$
\mathrm{T}=\mathrm{To}+\mathrm{Ta}
$$

Being $\mathrm{T}$ is the vector of total magnetization, To is the vector of induced magnetization and Ta is the vector of remanent magnetization. The space is defined function $f(x, y, z)$.

Measurement data processing gradually, eliminating diurnal variation, affecting the normal field and regional background field, so that it can obtain the magnetic anomaly map of the study area. Then, using Butterworth filter, Lowpass filter, Highpass and Bandpass filter for data.

An analysis signal is:

$$
\text { As }=\sqrt{d x \cdot d x+d z \cdot d z}
$$

where, $d z$ is the vertical derivative, and $d x$ is the horizontal derivative.

The Fourier transform of a space domain function $\mathrm{f}_{(\mathrm{x})}$ is defined to be:

$$
\mathrm{f}_{(\mathrm{x})}=\frac{1}{2 \pi} \int_{-\infty}^{\infty} \overline{\mathrm{f}}(\omega) \cdot e^{-i \omega x} d \omega
$$

The reciprocal relation is:

$$
\mathrm{f}_{(\varpi)}=\frac{1}{2 \pi} \int_{-\infty}^{\infty} \overline{\mathrm{f}}(\omega) \cdot e^{-i \omega x} d x
$$

where, $\omega$ is an angular wavenumber in radians per ground_unit (for $x$ in ground_units). The wavenumber in cycles per ground_unit (r) is simply $\omega / 2 \pi$.

A line of data in the space domain can be thought of as a sequence of magnetic values at points along a straight line, each point separated by a constant distance. Such a line can be transformed to and from the wavenumber domain by use of a discrete (FFT). The equivalent data set in the wavenumber domain is commonly called a Transform. A Transform of a line consists of real and imaginary amplitude values as a function of wavenumber in cycles per original distance unit.

The susceptibility filter calculates the apparent magnetic susceptibility of the magnetic sources using the following assumptions: 
- The IGRF has been removed from the data.

- There is no remanent magnetization.

- All magnetic response is caused by a collection of vertical prisms of infinite depth and strike extent.

A susceptibility filter is, in fact, a compound filter that performs a reduction to the pole, downward continuation to the source depth, correction for the geometric effect of a vertical prism, and division by the total magnetic field to yield susceptibility:

$$
\begin{aligned}
L(k, \theta) & =\frac{1}{2 \pi F \cdot \mathrm{H}(\omega) \cdot \Gamma(\theta) \cdot \mathrm{K}(k)} \\
\mathrm{H}(\omega) & =e^{-h \omega} \\
\Gamma(\theta) & =\left(\sin I_{a}+i \cos I \cdot \cos (D-\theta)\right)^{2} \\
\mathrm{~K}(\omega) & =\left(\frac{\sin (a \omega)}{a \omega}\right)
\end{aligned}
$$

$\mathrm{H}(\omega)$ Downward continuation to $h$

$\Gamma(\theta) \quad$ Reduction to the pole

$\mathrm{K}(\omega)$ Geometric factor of a vertical prism -- $(2 a \bullet \infty \bullet \infty$ in dimension $)$

where, $h$ is the depth in ground_units, relative to the observation level at which to calculate the susceptibility. $I_{a}$ is pole reduction amplitude inclination. Inclination to which to use the phase component only in the reduction to the pole. The default is \pm 20 . If $\left|I_{a}\right|$ is specified to be less then $|I|$, it is set to $I . I$ is geomagnetic inclination. $D$ is geomagnetic declination. $F$ is total geomagnetic field strength.

Each of these filters starts with a line of data in the space domain and produces a new line of data in the space domain that is the result of applying the filter.

\subsection{Hilbert Transform}

The Hilbert Transform option does the Hilbert Transform by the means of FFT based on the following known relation:

$$
\mathrm{F}[\mathrm{H}[\mathrm{f}(\mathrm{x})]]=-\mathrm{isgn}(\mathrm{w}) \mathrm{F}[\mathrm{f}(\mathrm{x})]
$$

where, $F[f(x)]$ is the Fourier transform of $f(x), H[f(x)]$ is the Hilbert transform of $f(x)$, and:

$$
\operatorname{Sgn}(\mathrm{w})=\mathrm{w} /|\mathrm{w}|=+1 \text { for } \mathrm{w}>0,=0 \text { for } \mathrm{w}=0,=-1 \text { for } \mathrm{w}<0 \text {. }
$$

Firstly, forward FFT transform of the input channel. Three output channels are created (this is only for the none-array input channel case). They will have the same name as the input channel but extension "_r” and “_i” for real and imaginary components of the transform, and “_w” for the wave number in radians/fiducial. (Note that the trend has been removed before FFT) Note that the output values are the real and imaginary components of the positive frequencies of the transform. Since we are dealing with the real-valued space domain problem, the negative part of the spectrum is simply the conjugate of the corresponding positive part, i.e. $h(-f)=[h(f)]^{*}$, and is not included in the output. The fiducial number will be in cycles/fiducial. The wave number channel will be in radians/fiducial.

Then, the one-dimensional Hilbert transform operator -isgn(w) is applied to the FFT transformed data. Finally, the inverse FFT transform to obtain the Hilbert transform results into the output channel. For the real data practice, it is suggested to remove trend line based on all data points (the default) before FFT process to prevent the discontinuity from the data two edges. The removed trend will be replaced back in the same manner as it removed after FFT. For the real data practice, it is also suggested to expand the data 10\% before FFT process to prevent the discontinuity from the data two ends. The first extend data by the user required \% points, then further extend to the number of the power of 2 for the FFT process. For instance, if the original data contains 60 points, then the values will be padded with $10 \%$, or 6 points at the end, giving 66 points. This will then be extended to the next power of 2, or 128 points, to do the FFT.

The extended area will be interpolated by Maximum Entropy Prediction (MEP) method. MEP samples the original data points to determine its spectral content. It then predicts a data function that will have the same 
spectral signature as the original data. As a result, the predicted data will not significantly alter the energy spectrum that would result from the original data alone.

\section{Application Analysis Data and Interpretation}

Study area is smaller, the terrain changes sharply, exposed three meaning. As we all know, remanence intensity limestone value is very low, and ore bearing rock body can cause remanent intensity is high, so it can be based on this to find ore bearing rock.

Magnetic anomaly map obtained shows "Figure 3", the small scale anomalies are small to medium strength. We conduct filtering process and derivation, respectively filtered derivation in the horizontal direction and the vertical direction, and then the analytic signal strength. Signal intensity greater than 2 is mainly concentrated in a certain range. The next task is to mark the range, calculated remanence magnetization intensity as based on abnormal volume on the strength of the remanent magnetization, changes in the range of $0.005-0.2$ cgs.

Then, the FFT Hilbert transform can be used to determine the prisms high remanence magnetization, the depth and size of prisms caused by magnetic anomalies. The results showed that "Figure 4", intrusive rock mineralization caused by abnormal position in the range of $60-700 \mathrm{~m}$ below the surface of terrain, extends the scale of ore rock mass $50-300 \mathrm{~m}$.

Through the study of geology, structure, mineralization regularity and geophysical survey work, the analysis and interpretation of display, has found that 5 of concealed ore bearing intrusive rock branch. Borehole samples display, metal element intrusive body containing molybdenum and copper mineralization. Combined with other drilling data, identified 5 small scale ore bearing intrusive rock branch, ensure they are Mo-Cu ore body not largely.

Through drilling compared with construction completed, the results of measurement data of magnetic method and drilling results are basically consistent, accurate rate reached more than 85\%.

\section{Conclusion}

1) By using FFT transform filter, in the horizontal and vertical derivative, and the use of FFT for Hilbert

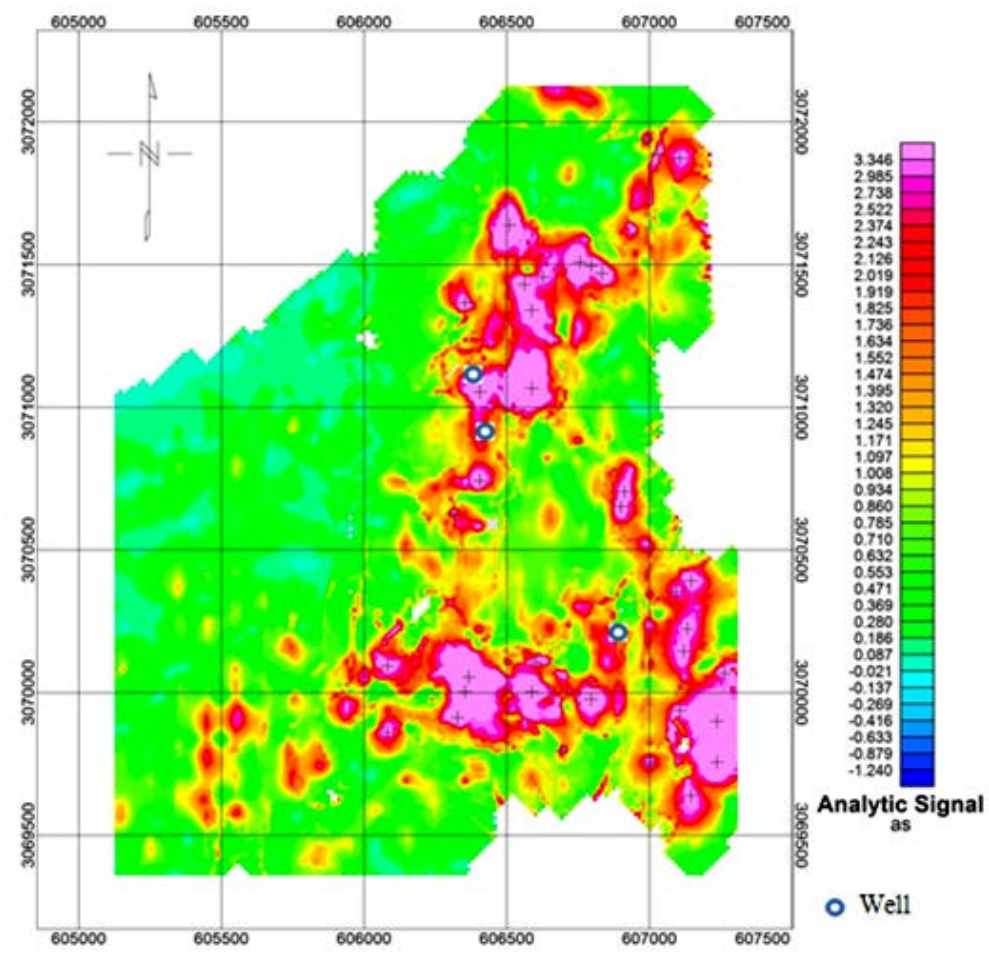

Figure 3. The magnetic data interpretation anomalous of Laba molybdenum (-copper) ore field.. 


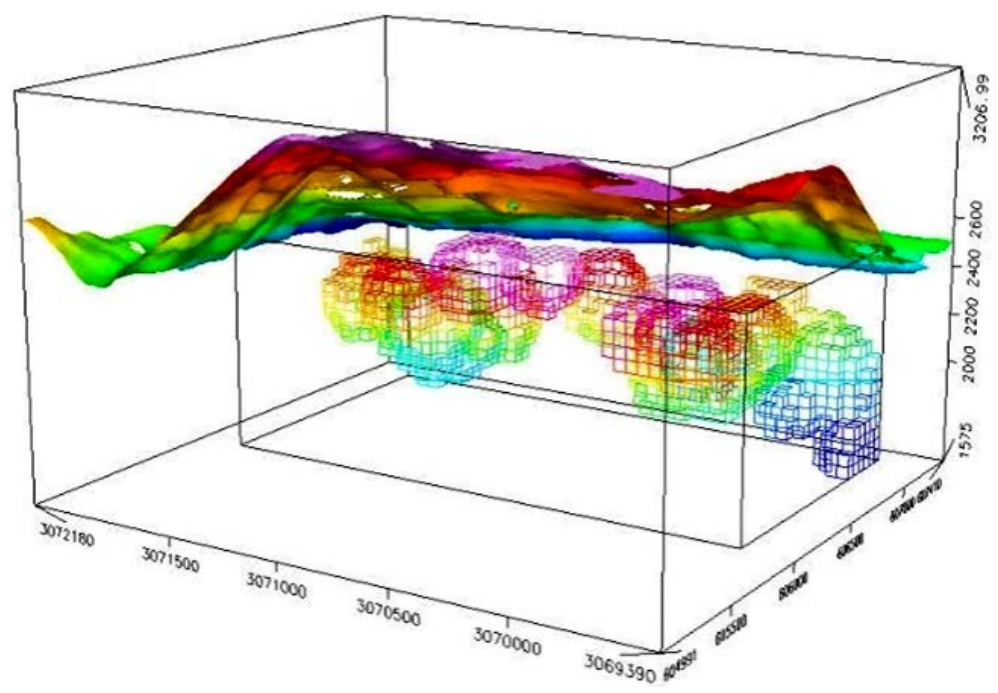

Figure 4. The concealed ore-bearing intrusion bodies of Laba molybdenum (-copper) ore field.

transform processing magnetic data, to determine the intrusive rock size and depth, effective for small anomalies size porphyry deposit and buried shallow, results and drilling revealed the coincidence rate reached above $85 \%$.

2) According to the analysis and interpretation of results, other magnetic anomalies should be concealed ore-body Mo-Cu instructions, can be verified.

\section{Acknowledgements}

This study is financially supported by the Doctoral Fund Projects of Education Ministry of China (20125314110006), the Natural Science Fund Project of Yunnan Province (2009CI030) and the Science and Technology Project of Yunnan Baofeng Mineral Resource Co. Ltd. We thank Mr. Shilei Li and other geological engineers for their help during the field work. We sincerely thank Dr. Haixia Li and other reviewers for their comments and suggestions.

\section{References}

Alanna, C. D., \& Yára, R. M. (2009). Gravity and Magnetic 3D Inversion of Morro do Engenho Complex, Central Brazil. Journal of South American Earth Sciences, 28, 193-203. http://dx.doi.org/10.1016/j.jsames.2009.02.006

Eun-Jung, H., Shih, C., Peter, K., Michael, D., Barry, B., \& Matthew, H. (2011). Automatic Identification of Responses from Porphyry Intrusive Systems within Magnetic Data Using Image Analysis. Journal of Applied Geophysics, 74, $255-262$. http://dx.doi.org/10.1016/j.jappgeo.2011.06.016

Fabio, C. T. (2012). Rapid Interactive Modeling of 3D Magnetic Anomalies. Computers \& Geosciences, 48, 308-315. http://dx.doi.org/10.1016/j.cageo.2012.01.006

Wang, G. W., Zhu, Y. Y., Zhang, S. T., Yan, C. H., Song, Y. W., Ma, Z. B., Hong, D. M., \& Chen, T. Z. (2012). 3D Geological Modeling Based on Gravitational and Magnetic Data Inversion in the Luanchuan Ore Region, Henan Province, China. Journal of Applied Geophysics, 80, 1-11. http://dx.doi.org/10.1016/j.jappgeo.2012.01.006

Hou, Z. Q., Yang, Y. Q., Wang, H. P. et al. (2003). Collision-Orogenic and Mineralization Systems of the Yidun Arc Orogen in Sanjiang Region, China. Beijing: Geological Publishing House, 156-160. (in Chinese with English abstract)

Ilya, P., \& Ahmed, S. (2009). Gravity and Magnetic Data Inversion for 3D Topography of the Moho Discontinuity in the Northern Red Sea Area, Egypt. Journal of Geodynamics, 47, 237-245. http://dx.doi.org/10.1016/j.jog.2008.12.001

Li, W. C., Yu, H. J., Yin, G. H., Cao, X. M., Huang, D. Z., \& Dong, T. (2012). Re-Os Dating of Molybdenite from Tongchanggou Mo-Polymetallic Deposit in Northwest Yunnan and Its Metallogenic Environment. Mineral Deposits, 31, 282292. (in Chinese with English abstract)

Maysam, A., Ali, G., Gholam-Hossain, N., \& Nader, F. (2013). Fast Inversion of Magnetic Data Using Lanczosbidiagonalization Method. Journal of Applied Geophysics, 90, 126-137. http://dx.doi.org/10.1016/j.jappgeo.2013.01.008

Pejman, S., Michel, C., \& Denis, M. (2011). 3D Stochastic Inversion of MAGNETIC Data. Journal of Applied Geophysics, 
73, 336-347. http://dx.doi.org/10.1016/j.jappgeo.2011.02.005

Peng, H. J., Mao, J. W., Pei, R. F., Zhang, C. Q., Tian, G., Zhou, Y. M., Li, J. X., \& Hou, L. (2014). Geochronology of the Hongniu-Hongshan Porphyry and Skarn Cu Deposit, Northwestern Yunnan Province, China: Implications for Mineralization of the Zhongdian Arc. Journal of Asian Earth Sciences, 79, 682-695. http://dx.doi.org/10.1016/j.jseaes.2013.07.008

Stocco, S., Godio, A., \& Sambuelli, L. (2009). Modelling and Compact Inversion of Magnetic Data: A Matlab Code. Computers \& Geosciences, 35, 2111-2118. http://dx.doi.org/10.1016/j.cageo.2009.04.002

Vanessa, B. R., Vinicius, H. A. L., \& Marta, S. M. M. (2013). 3D Inversion of Magnetic Data of Grouped AnomaliesStudy Applied to São José Intrusions in MatoGrosso, Brazil. Journal of Applied Geophysics, 93, 67-76. http://dx.doi.org/10.1016/j.jappgeo.2013.03.013

Yang, Y. S., Li, Y. Y., Liu, T. Y., Zhan, Y. L., \& Feng, J. (2011). Interactive 3D forward Modeling of Total Field Surface and Three-Component Borehole Magnetic Data for the Daye Iron-Ore Deposit (Central China). Journal of Applied Geophysics, 75, 254-263. http://dx.doi.org/10.1016/j.jappgeo.2011.07.010 